Gut, 1978, 19, 910-915

\title{
Lundh test and ERCP in pancreatic disease
}

\author{
M. G. ASHTON, A. T. R. AXON, AND D. J. LINTOTT \\ From the Gastroenterology Unit, Professorial Medical Unit and Department of Diagnostic Radiology, \\ the General Infirmary, Leeds
}

SUMMARY The Lundh test and endoscopic retrograde cholangiopancreatography (ERCP) were used to investigate 40 patients with known or suspected pancreatic disease. Pancreatograms were classified as being normal or showing minimal or gross changes. There was good correlation between the two tests in assessing the degree of pancreatic disease $(P<0.01)$. Gross radiographic changes were associated with a mean tryptic activity (MTA) of $<6 \mathrm{IU} / \mathrm{ml}$, while minimal changes were associated with an MTA between 6 and $14 \mathrm{IU} / \mathrm{ml}$. Although some patients with normal pancreatograms had MTAs within this range, no patients with an MTA above $14 \mathrm{IU} / \mathrm{ml}$ had an abnormal pancreatogram. The Lundh meal is of great value in detecting extensive pancreatic disease and an unequivocally normal result virtually excludes significant chronic pancreatic disease. Values in the equivocal range usefully draw attention to early pancreatitis which may be confirmed by ERCP. In this paper the interpretation of pancreatograms is discussed and the clinical features of the patients with minimal change disease are reviewed.

The Lundh test is well established as a simple means of assessing pancreatic exocrine function and it has been shown to have a good diagnostic success rate in detecting severe pancreatic disease, (Lundh, 1962; Cook et al., 1967; Mottaleb et al., 1973; James, 1973; Waller, 1975a). Most workers have defined the test as being normal or abnormal on the basis of a specific diagnostic parameter (usually mean tryptic activity) below which gross pancreatic disease seems certain. There has been difficulty in the interpretation of equivocal results marginally above this parameter because there appears to be a wide range of normality and because non-pancreatic conditions-for example, gastric surgery and coeliac disease-may give results within this range. It has not been established whether the Lundh test can detect moderate or minimal pancreatic disease. Indeed, it has been suggested that extensive dumage must be present before pancreatic exocrine function is significantly diminished and that severe focal pancreatic damage may occur without a reduction in exocrine secretion (Waller, 1975b). In this regard, the direct stimulation tests (secretin or secretin/pancreozymin tests) have been thought to be more sensitive in detecting mild pancreatic damage (Gyr et al., 1975), while the Lundh test has been shown to be just as effective in the diagnosis of gross pancreatic disease (Gyr et al., 1975; Waller, 1975a).

Received for publication 4 May 1978
Pancreatography, on the other hand, shows a wide spectrum of structural changes in pancreatic disease (Kasugai et al., 1974; Cotton, 1977), but caution is required in interpreting minor radiographic abnormalities and there may be considerable observervariation in the reporting of pancreatograms (Reuben et al., 1976; Cotton, 1977; Kizu et al., 1977). Salmon et al. (1975) showed a good correlation between pancreatic function tests and pancreatography and suggested that both investigations could detect minimal-change pancreaticis. Nakano et al. (1974) found considerable discrepancy between morphological and functional tests. Dobrilla et al. (1976) showed a good correlation between pancreatogram abnormalities and the secretin-pancreozymin test but the correlation occurred only in patients with proven chronic pancreatitis. We have used both tests in the investigation of patients with known or suspected pancreatic disease.

\section{Methods}

\section{PATIENTS}

The patients investigated were those with symptoms suggestive of pancreatic disease who were referred for ERCP. The main symptoms were abdominal pain, diarrhoea, clinical steatorrhoea, unexplained weight loss, jaundice, diabetes mellitus of late onset, and patients who had had previous acute or recurrent pancreatitis. 


\section{LUNDH TESTS}

This was performed on the day before ERCP, except in one instance, and the two-hour mean tryptic activity (MTA) in IU per $\mathrm{ml}$ was estimated using the method described by Cook et al. (1967).

\section{PANCREATOGRAMS}

Only successful pancreatograms with satisfactory filling of the duct system were accepted. These were reviewed independently by two observers with experience of 300 examinations. The pancreatograms were reviewed without clinical information and knowledge of the outcome of the Lundh test. Where there was disagreement, a third experienced opinion was used to arbitrate. A modification of the classification of Kasugai et al. (1974) was used to grade the pancreatograms into normal, minimal change, or gross change (Table 1). The main difference between this classification and Kasugai's was that the intermediate category of 'moderate' change was omitted

Table 1 Criteria used to assess pancreatograms (modified from Kasugai (1974))

\begin{tabular}{lll}
\hline & \multicolumn{2}{l}{ Assessment of pancreatograms } \\
\cline { 2 - 3 } & Gross change & Minimal change \\
\hline Main duct & & \\
Irregular calibre & + & $+^{*}$ \\
Stenosis with dilatation & + & - \\
Obstruction & + & - \\
Dilatation & + & - \\
Calculi & + & - \\
Cysts & + & + \\
Branch ducts & ++ & + \\
Dilatation & ++ & + \\
Nipping & ++ & + \\
Irregular calibre & ++ & - \\
Irregular distribution & + & \\
Parenchyma & + & \\
Coarse opacification & & \\
\hline
\end{tabular}

*Segmental.

and the terms 'rigidity' and 'tortuosity', which can be confusing when describing duct abnormalities, were avoided. Thus, the features taken as indicative of gross change were (1) main duct abnormalities in the head or body in the form of either irregular dilatation ('chain of lakes' appearance) or, less commonly, irregular narrowing; or localised stenosis with dilatation of the main duct beyond; or complete obstruction; (2) marked abnormalities of the sidebranches throughout the whole gland; (3) coarse opacification of the whole gland, which is distinct from the fine acinar filling in the head, which may occur in normal subjects due to overfilling of the duct system or by the cannula being impacted in a side branch in the head of the gland; (4) calculi or cysts.

Any one of these features was accepted as evidence of gross change but in practice (3) was not observed in the absence of other features. The signs of minimal change were (a) calibre irregularity of the main duct confined to the tail or segmental narrowing without dilatation beyond; (b) focal side-branch abnormalities, less marked than in gross change, but affecting at least three branches. These changes were 'nipping' at the origin of side branch from the main duct, loss of tapering, frank dilatation, abrupt truncation or irregular distribution-that is, abnormal course and branching pattern. (Note that the word 'change' was used rather than disease because morphological rather than pathological features were assessed, although overall correlation is likely-see discussion.)

All results were compared using the Mann-Whitney $\mathrm{U}$ test, a non-parametric method for two independent samples (Siegel, 1956).

\section{Results}

Forty patients underwent both successful Lundh test and pancreatography. The pancreatograms were assessed independently and on only five occasions was there disagreement between the two observers (Table 2). Nineteen patients had normal pancreatograms, 10 patients minimal change pancreatograms, and 11 patients gross change pancreatograms. Only one patient in the latter group had pancreatic calcification on the plain control abdominal radiographs. The MTAs of the three groups are shown in the Figure.

Table 2 Results of pancreatogram assessment by two observers

\begin{tabular}{lcccc}
\hline & \multicolumn{3}{l}{ Pancreatogram assessment } \\
\cline { 2 - 4 } & Normal & Minimal & Gross \\
\hline Agreement in 35 & 17 & 7 & 11 \\
Disagreement in 5 & & $\leftarrow$ & & 1 \\
Third opinion & 2 & 3 & 11 \\
Total & 19 & 10 & 11 \\
\hline
\end{tabular}

NORMAL PANCREATOGRAMS

Nineteen patients had normal pancreatograms and their MTAs ranged from $6.9 \mathrm{IU} / \mathrm{ml}$ to $26 \mathrm{IU} / \mathrm{ml}$ with a mean of $15.4 \mathrm{IU} / \mathrm{ml}$. However, if the distribution is considered log/normal (Mottaleb, 1973) the mean is $14.6 \mathrm{IU} / \mathrm{ml}$ with a theoretical range between 7.0 and $30 \mathrm{IU} / \mathrm{ml}$ (antilog of $\log$ mean $\pm 2 \log \mathrm{SD}$ ). The clinical features are shown in Table 3.

MINIMAL CHANGE PANCREATOGRAMS Ten patients had minimal change pancreatograms and their MTAs ranged from 5.0 to $13.4 \mathrm{IU} / \mathrm{ml}$ with a mean of $9.0 \mathrm{IU} / \mathrm{ml}(\log$ mean $8.7 \mathrm{IU} / \mathrm{ml}$; log range 4.6 to $16 \mathrm{IU} / \mathrm{ml})$. These results were statistically 


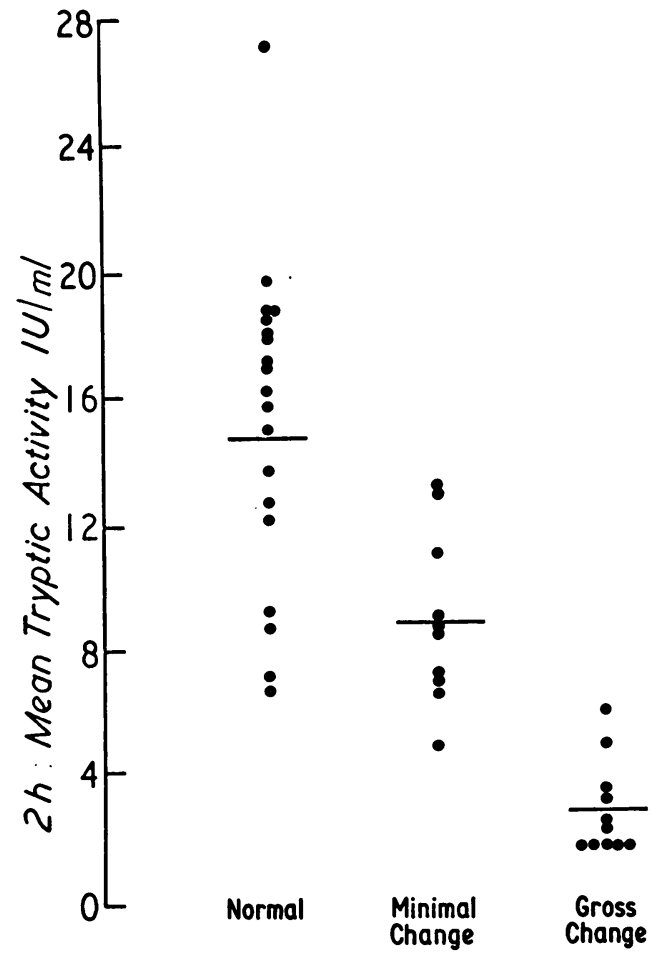

Figure The two hour MTA $(I U / m l)$ of the patients grouped according to pancreatogram findings. The lines shown represent the arithmetical mean of each group. different from those of the patients with normal pancreatograms $(P<0.01)$ (Mann-Whitney $U$ test). The clinical features of these patients are shown in Table 4.

\section{GROSS CHANGE PANCREATOGRAMS}

Eleven patients had gross pancreatic disease on pancreatography, and their MTAs were correspondingly depressed, ranging from 6.3 to less than 2.0 $\mathrm{IU} / \mathrm{ml}$ (mean $3.2 \mathrm{IU} / \mathrm{ml}, \log$ mean $2.8 \mathrm{IU} / \mathrm{ml}$ ). These results were statistically different from those of both the normal and minimal change disease patients ( $P<0.01$, Mann-Whitney U test).

The clinical features are shown in Table 5.

\section{Discussion}

Our study confirms that there is a good correlation between pancreatography and the Lundh test in assessing the degree of pancreatic damage. In particular, it shows that there is a significant depression $(P<0.01)$ of the measured mean tryptic activity in those patients with minimal changes on pancreatography as compared with those with normal pancreatograms; the Lundh test is able to detect minimal pancreatic damage but, unfortunately, in doing so, it cannot absolutely differentiate this condition from normal. Pancreatography is required to help establish the presence of minimal pancreatic disease. Thus when the Lundh test is used to investi-

Table 3 Clinical features of patients with normal pancreatograms

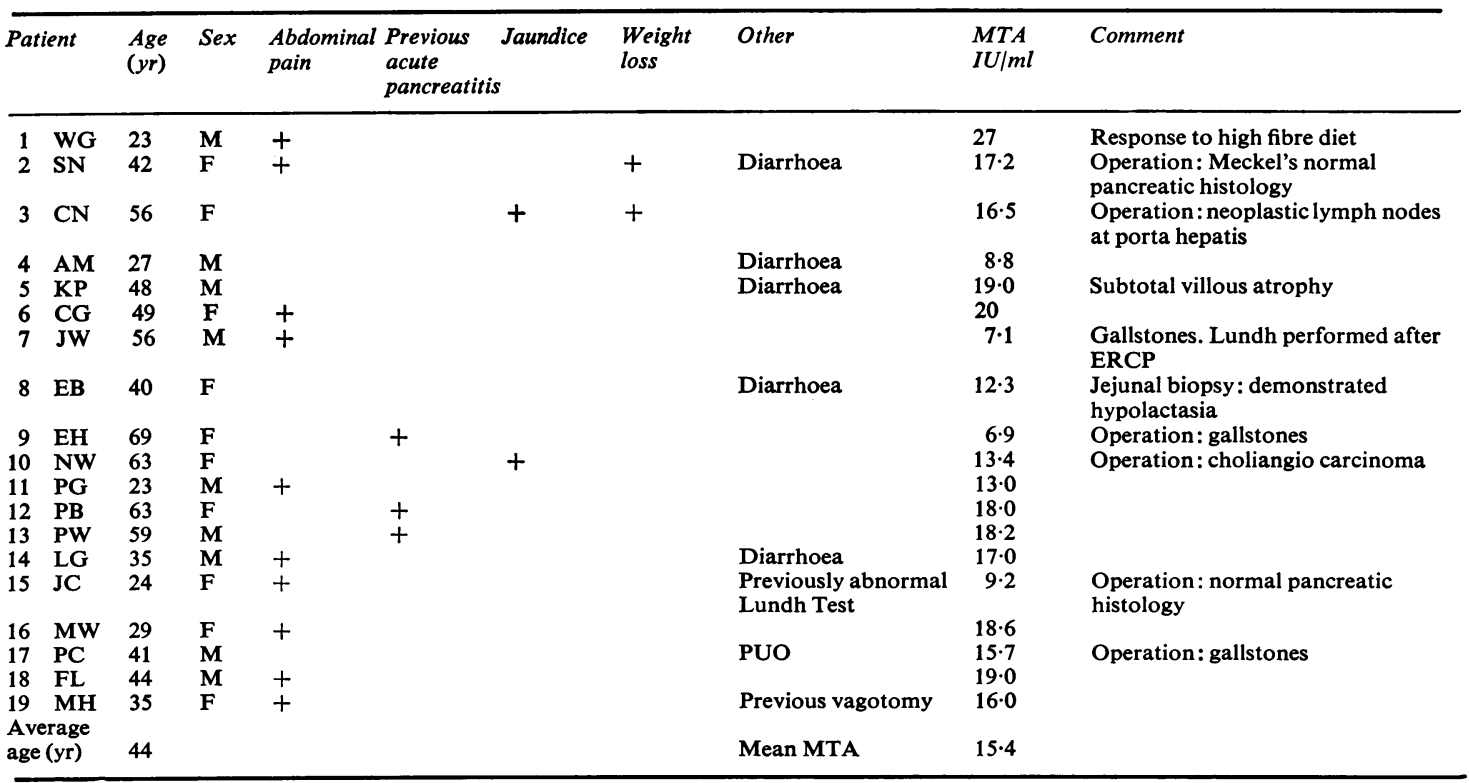


Table 4 Clinical features of patients with minimal change pancreatograms

\begin{tabular}{|c|c|c|c|c|c|c|c|c|c|c|}
\hline \multicolumn{2}{|c|}{ Patient } & \multirow{2}{*}{$\begin{array}{l}\text { Age } \\
(y r)\end{array}$} & \multirow{2}{*}{$\begin{array}{l}\text { Sex } \\
\mathrm{M}\end{array}$} & $\begin{array}{l}\text { Abdominal } \\
\text { pain }\end{array}$ & $\begin{array}{l}\text { Previous J } \\
\text { acute } \\
\text { pancreatitis }\end{array}$ & Jaundice & $\begin{array}{l}\text { Weight } \\
\text { loss }\end{array}$ & Other & \multirow[t]{2}{*}{$\begin{array}{l}M T A \\
I U / m l\end{array}$} & Comment \\
\hline 1 & NB & & & + & + & & & & & \\
\hline 2 & MW & 63 & $\mathbf{F}$ & + & + & & & & $5 \cdot 0$ & \\
\hline 3 & TG & 68 & $\mathbf{M}$ & + & + & & & Previous biliary surger & ry $9 \cdot 0$ & \\
\hline 4 & $\mathbf{R W}$ & 48 & $\mathbf{M}$ & + & + & & & $\begin{array}{l}\text { Late onset diabetes } \\
\text { mellitus, duodenal } \\
\text { ulcer }\end{array}$ & $11 \cdot 2$ & \\
\hline 5 & RS & 53 & $\mathbf{M}$ & + & + & & & $\begin{array}{l}\text { Late onset diabetes } \\
\text { mellitus, previous } \\
\text { truncal vagotomy }\end{array}$ & $8 \cdot 8$ & \\
\hline 6 & JP & 49 & $\mathbf{M}$ & & & + & + & Clinical steatorrhoea & $7 \cdot 2$ & $\begin{array}{l}\text { Papilloma of ampulla with focal } \\
\text { pancreatitis at operation }\end{array}$ \\
\hline 7 & DF & 55 & $\mathbf{F}$ & + & & & & $\begin{array}{l}\text { Previous biliary } \\
\text { surgery, duodenal ulce }\end{array}$ & er 13.4 & \\
\hline 8 & LM & 24 & $\mathbf{F}$ & + & & & & Diarrhoea & $7 \cdot 1$ & \\
\hline 9 & HG & 63 & $\mathbf{F}$ & + & & & + & $\begin{array}{l}\text { Late onset diabetes } \\
\text { mellitus, primary } \\
\text { biliary cirrhosis }\end{array}$ & $13 \cdot 2$ & \\
\hline 10 & JE & 53 & $\mathbf{M}$ & & & & + & $\begin{array}{l}\text { High alcohol } \\
\text { consumption }\end{array}$ & $9 \cdot 2$ & \\
\hline $\begin{array}{l}\text { Ave } \\
\text { age }\end{array}$ & $\begin{array}{l}\text { erage } \\
\text { (yr) }\end{array}$ & 52 & & & & & & Mean MTA & $9 \cdot 0$ & \\
\hline
\end{tabular}

Table 5 Clinical features of patients with gross change pancreatograms

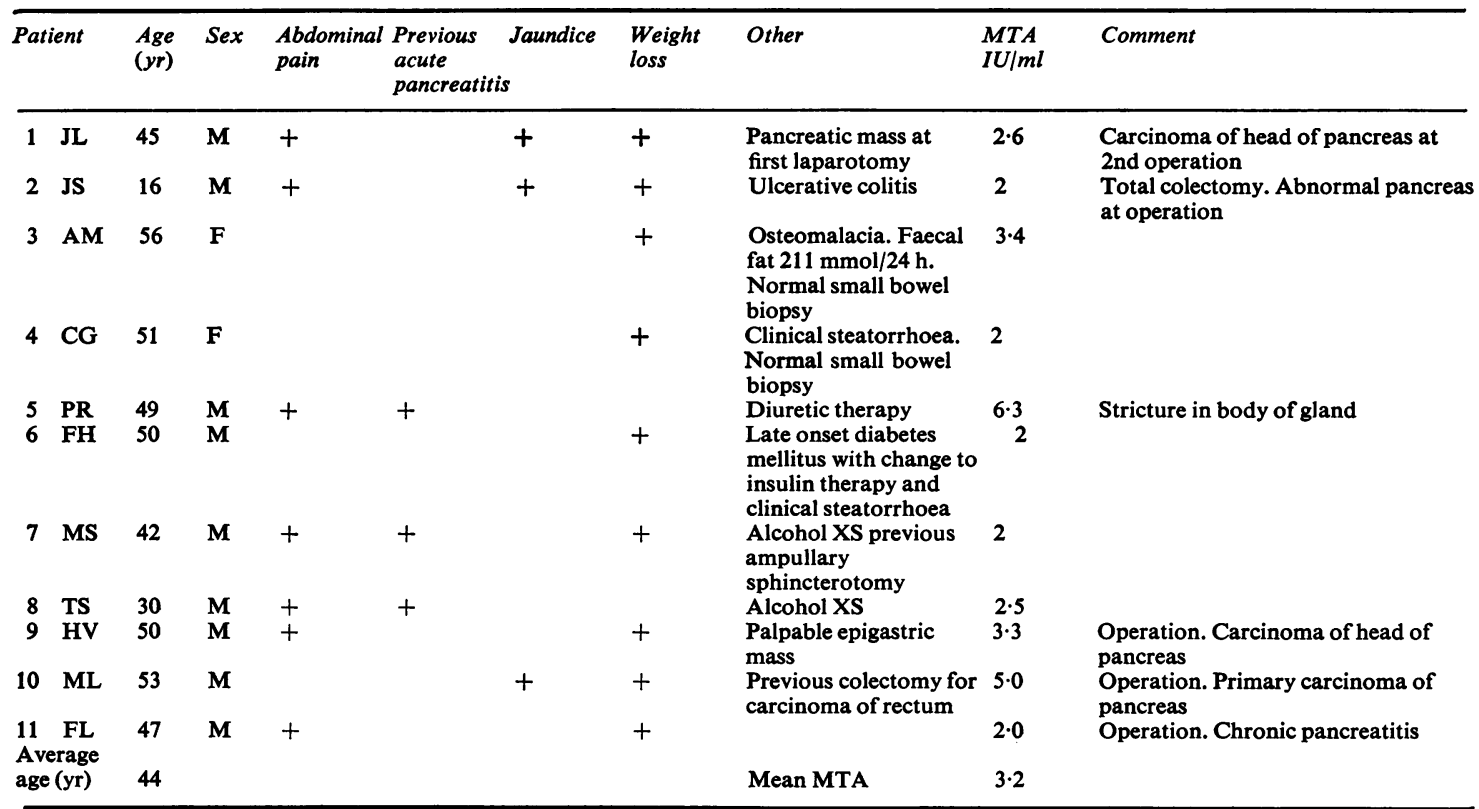

gate suspected pancreatic disease a result which falls within the 'equivocal' range (6-14 IU/ml) cannot be discounted as irrelevant and should be regarded as a reason for further investigation by pancreatography. This is contrary to the previous concept of reporting Lundh tests as either normal or abnormal (or positive or negative). Most workers (Cook et al., 1967; Mottaleb et al., 1973; Zietlin and Sircus, 1974) found that some of their patients with proven pancreatic disease gave results above their defined abnormal range but they make no reference to the actual severity of the condition. Similarly, they suggest that some results falling just above their grossly abnormal range are in fact abnormal, but in discussion they emphasise other non-pancreatic conditions which may give results within this range. The range of normality is wide (Waller, 1975a) and Mottaleb et al. (1973) found that normal subjects (including healthy 
controls) had a log-normal distribution with a mean of $16.8 \mathrm{IU} / \mathrm{ml}$ and a range of 7.0 to $38 \mathrm{IU} / \mathrm{ml}$ (antilog of (log mean $\pm 2 \log$ SD)) which, on a linear scale, means the distribution is skewed positively towards lower values. This inevitably means that there is overlap between normal and minimally abnormal; our study confirms this (our study $\log$ mean $14 \cdot 56$, range $7 \cdot 0-30 \mathrm{IU} / \mathrm{ml}$ ). The results presented heie show that an MTA below 6.0 $\mathrm{IU} / \mathrm{ml}$ indicates severe structural changes within the pancreas.

Endoscopic pancreatography is a relatively new technique in the investigation of pancreatic disease but it has already established itself as a valuable diagnostic tool. There are, however, some problems with the interpretation of the pancreatograms. Reuben et al. (1976) showed that there was a significant observer-variation, particularly in regard to differentiating pancreatitis from carcinoma when clinical details are withheld. Kizu et al. (1976) showed that not all apparent abnormalities in the pancreatogram are significant; his, however, was a necropsy study, which may not necessarily reflect the clinical situation. Cotton (1977), in a recent excellent review of ERCP, concludes that earlier diagnosis of chronic pancreatitis required better documentation of minor pancreatographic changes, and their comparison with other investigations.

Bearing these points in mind, we have reviewed our pancreatograms as described above. There was good agreement between the two observers (Table 2) but, as one would expect, problems mainly arose in differentiating 'normal' from 'minimal change'. Although minor changes in branch ducts may be difficult to assess and different observers may not agree in specific cases, the results show that they are associated with diminished exocrine function. This is not surprising. Nakamura et al. (1972) has shown that pathological changes progress from small ducts to larger ones and it is to be expected that early chronic pancreatic disease will show minor changes in the side branches only.

The clinical features of the normal group are shown in Table 2 and in no instance has a diagnosis of chronic pancreatic disease been established subsequently. Seven patients had an ultimate operative diagnosis with three patients having gallstones, two patients neoplastic biliary disease, and two patients had normal pancreatic histology obtained during laparotomy. A further patient was shown to have subtotal villous atrophy and another patient, who had a low lactase level on analysis of jejunal mucosa, subsequently had a good symptomatic reponse to a lactose free diet. One patient subsequently had a good response to a high fibre diet, leaving nine patients without an established diagnosis.

Four patients with pancreatograms assessed as normal had MTAs well into the equivocal range $(<12$ $\mathrm{IU} / \mathrm{ml}$ ). Of these, one patient (patient 7), an exception in this study, had the Lundh test performed the day after ERCP; at operation, gallstones were confirmed and the pancreas felt normal. Pancreatography may have temporarily depressed exocrine function. Another patient (patient 15) had been investigated at a different hospital where the Lundh test was also found to be equivocal. Laparotomy subsequently revealed a macroscopically normal pancreas and pancreatic biopsy showed normal histology. A third patient (patient 9) had suffered three episodes of acute pancreatitis and has since been found to have gall stones. The fourth patient (patient 4 ) has a raised faecal fat $(20 \mathrm{mmol} / 24 \mathrm{~h})$ but other investigations have all been normal. It seems probable, on clinical grounds, that one of these patients at least has genuine chronic pancreatitis missed at pancreatography. Pancreatograms show ductal abnormalities only and therefore the tendency will be to underdiagnose rather than overdiagnose with this technique.

The clinical features of the patients with minimal change disease are summarised in Table 3. There is strong clinical evidence of chronic pancreatitis in six patients. Five of them had at least one documented attack of acute pancreatitis and subsequently continued to have abdominal pain (no patient was investigated within three months of an acute episode). These patients probably have chronic relapsing pancreatitis; two of them were diabetic. The sixth patient underwent laparotomy and was found to have focal pancreatitis around a papilloma in the head of the pancreas. The clinical evidence for pancreatitis in patients 7-10 is less persuasive.

Kizu et al. (1977) found that calibre changes of branch ducts were much more common in old agethat is, $>60$ years-and may have no diagnostic significance. However, the average age of the patients in the minimal change group was 52 years; only three patients were over 60 years old. This was only slightly older than both the average of the normal and gross change group (44 years) and age alone is therefore unlikely to be a significant factor in determining these pancreatogram abnormalities.

The clinical features of patients with gross change disease are shown in Table 5. Five patients came to laparotomy, three having carcinoma confirmed and two showing chronic pancreatitis. The average age was 44 , the same as the normal group but slightly younger than the minimal change group. In two cases (patients 7 and 8) the clinical picture was of recurrent acute pancreatitis, associated with high alcohol intake, but the Lundh test showed exocrine 
insufficiency in both patients, confirming the diagnosis of chronic relapsing pancreatitis.

An effective, non-invasive test for pancreatic disease is urgently needed for patients presenting with abdominal symptoms; those currently available are expensive and time-consuming and still leave a large number of patients in an equivocal group. Apart from our failure to provide patients with an explanation for their symptoms, our knowledge of the pathogenesis of pancreatitis must remain sketchy if we are unable to reach a diagnosis earlier in the history of the illness. The group of patients we have reported with minimal disease represents only a small proportion of the total number of patients with early pancreatitis, which is difficult to diagnose. There may be even larger numbers with asymptomatic disease, a study of which might lead to a better understanding of the disease process.

We would like to thank the Leeds Teaching Hospital Special Trustees for providing financial support for the radiographic assistance needed in this study.

\section{References}

Cook, H. B., Lennard-Jones, J. E., Sherif, S. M., and Wiggins, H. S. (1967). Measurement of tryptic activity in intestinal juice as a diagnostic test of pancreatic disease. Gut, 8, 408-414.

Cotton, P. B. (1977). ERCP. Gut, 18, 316-341.

Dobrilla, G., Fratton, A., Valentini, M., Vantini, I., Cavallini, G., Angelini, G., Mirachian, R., and Mora, R. (1976). Endoscopic retrograde pancreatography and secretinpancreozymin test in diagnosis of chronic pancreatitis: a comparative evaluation. Endoscopy, 8, 118-123.

Gyr, K., Agrawal, N. M., Felsenfeld, O., and Font, R. G. (1975). Comparative study of secretin and Lundh tests.
American Journal of Digestive Diseases, 20, 506-512.

James, O. (1973). The Lundh test. Gut, 14, 582-591.

Kasugai, T., Kuno, N., and Kizu, M. (1974). Manometric endoscopic retrograde pancreatocholangiography. Technique, significance and evaluation. American Journal of Digestive Diseases, 19, 485-502.

Kizu, M., Newman, J., Cotton, P B., and Kasugai, T. (1977). Histological correlations with pancreatography in necropsy specimens (Abstract). Gut, 18, 399-400.

Lundh, G. (1962). Pancreatic exocrine function in neoplastic and inflammatory disease, a simple and reliable new test. Gastroenterology, 42, 275-280.

Mottaleb, A., Kapp, F., Noguera, E. C. A., Kellock, T. D., Wiggins, H. S., and Waller, S. L. (1973). The Lundh test in the diagnosis of pancreatic disease; a review of five years experience. Gut, 14, 835-841.

Nakamura, K., Sarles, H., and Payan, H. (1972). Threedimensional reconstruction of the pancreatic ducts in chronic pancreatitis. Gastroenterology, 62, 942-949.

Nakano, S., Horiguchi, Y., Takeda, T., Suzuki, T., and Nakajima, S. (1974). Comparative diagnostic value of endoscopic pancreatography and pancreatic function tests. Scandinavian Journal of Gastroenterology, 9, 383-389.

Reuben, A., Elias, E., Hatfield, A. R. W., Kizu, M., Pemberton, J., and Cotton, P. B. (1976). Observer variation in pancreatogram interpretation (Abstract). Gut, 17, 827.

Salmon, P. R., Baddeley, H., Machado, G., Low-Beer, T., Rhys-Davies, E., and Trapnell, J. (1975). Endoscopic pancreatography, scintigraphy and exocrine function in pancreatitis: A comparative study (Abstract). Gut, 16, 830831.

Siegel, S. (1956). Nonparametric Statistics for the Behavioral Sciences, pp. 116-127. McGraw-Hill: New York.

Waller, S. L. (1975a). The Lundh test in the diagnosis of pancreatic disease: a comment from the Moderator (Symposium on diagnosis of pancreatic disease.) Gut, 16, 657-658.

Waller, S. L. (1975b). The aetiology of pancreatitis. In Topics in Gastroenterology, 3, pp. 97-116. Edited by S. C. Truelove and M. J. Goodman. Blackwells: Oxford.

Zeitlin, I. J., and Sircus. W. (1974). Factors influencing duodenal trypsin levels following a standard test meal as a test of pancreatic function. Gut, 15, 173-179. 